\title{
LEONARDO DA VINCI'S VIEWS ON ARTERIOSCLEROSIS*
}

OF all the characteristics of Leonardo's scientific work perhaps the most remarkable is his multilateral approach to any problem. His investigation of arteriosclerosis is no exception, for his final conception of the condition was reached by a combination of three separate fields of research. First, his study of hydrodynamics by which he came to appreciate many of the factors governing the flow of fluids in experimental glass tubes, rivers and canals. Secondly, in his study of anatomy where his observations on the effects of age on anatomical structures, particularly of blood vessels, played an inportant part. Thirdly, his concept of nutrition which added the final touch to his description of the process of thickening of the arterial wall.

\section{HYDRODYNAMIC STUDIES}

His investigations of the flow of fluids occupied throughout his life as much of Leonardo's attention as any. His experiments on this subject are numerous. They are to be found particularly in MSS. I and F which cover the decade 1498-1508. In these he develops the technique of the use of markers for all conditions of fluid flow using weighted floats, cork, leaves, bits of paper, the fine seed of panic-grass or coloured inks, as circumstances demanded. By dropping these markers into glass-walled tubes he visualized, for example, the flow of water pouring from a pipe, obtaining not only a qualitative pattern but some quantitative insight as well. In these experiments he not only demonstrated the rebound of a current of water from side to side of the pipe with eddy formation but showed that the angle of incidence equals the angle of reflection, and that the walls of the vessel thus receive intermittent areas of percussion which put them to stress (see Figure 1). For this reason he points out, no river as it ages continues to flow straight, it develops curves by erosion on one bank with deposit of debris on the other. Thus the older the river is the more tortuous it is. He illustrates this point in his map of the Arno. He demonstrates too, that the velocity of flow varies inversely with the dimensions of the river; the narrower it is the faster the flow and conversely. But whether a river is straight or tortuous, the quantity of flow is the same. Inequalities in these dimensions, local narrowings or dilations, lead to eddy formation, and eddies in particular percuss river banks leading to their wear and erosion, thus increasing tortuosity of the channel. Deposition of earth leads to localized silting up and obstruction of the channel.

These hydrodynamic principles were in his mind when he turned to his investigation of the blood vessels of man.

Throughout his life, Leonardo was keenly aware of the analogy between the macrocosm of the world and the microcosm of man. He was thus very ready to apply the physical laws that he discovered working in rivers, (the vessels of the macrocosm) to the vessels of the microcosm i.e. blood vessels in man.

\section{ANATOMY OF THE BLOOD VESSELS OF MAN}

Dissection of human bodies revealed to him a change from the straight blood

*This paper was read at the XXIII International Congress of the History of Medicine, London, 2-9 September 1972. 


\section{News, Notes and Queries}

vessels of youth to the tortuous vessels of age. As with rivers this corresponded with time. To the causes of this change he gave particular attention in his anatomical investigation of the 'old man' (il vecchio) which occupied him in the hospital of Santa Maria Nuova, Florence, about 1506. Several pages of the Anatomical Manuscript Folio B are devoted to an intensive study of the subject. Since these notes include all that Leonardo is known to have written on this problem I shall take the opportunity of presenting them in full.

On Fol. B 10 r. he depicts the contrast between the straightness of vessels in the young and their tortuosity in the old (see Figure 2). Under the heading, 'Nature of the Vessels in Youth and Age' he writes, 'In proportion as the Vessels become old their branches lose their straightness and become so much the more bent or tortuous, and their coats thicker, as old age becomes full of years.' And he here adds the note, 'I have also found in a decrepit man the mesenteric vessels constricting the passage of blood, and doubled in length.' This contrast between the straight vessels of youth and the distorted vessels of age impressed Leonardo so much that he repeats on Fol. B 22 r. 'I have found in the decrepit how the vessel which extends from the porta hepatis to the spleen passes behind the stomach and ramifies in the spleen; the vessels in the young are straight and full of blood, and in the old are tortuous, flattened, wrinkled and empty of blood.' He proceeds to correlate these changes with the cirrhotic state of the old man's liver (described more fully on Fol. B $10 \mathrm{v}$.).

On Fol. B 10 v. Leonardo goes into this subject with characteristic thoroughness, writing (see Figure 3),

The artery and vein which in the old extend between the spleen and the liver acquire so thick a coat that it contracts the passage of the blood which comes from the mesenteric vessels, which blood passes through the liver to the heart and two great vessels [the vena cava and aorta] and consequently through the whole body. These vessels apart from the thickness of their coats grow in length and become twisted like a snake; and the liver loses its sanguineous humour which was carried to it by the vein. Consequently this liver becomes desiccated and like congealed bran both in colour and substance so that when it is subjected to the slightest friction its substance falls away in small flakes like sawdust and leaves behind the veins and arteries ... And this old man, a few hours before his death told me that he had lived one hundred years and that he did not feel any bodily ailment other than weakness; and thus while sitting on a bed in the hospital of Santa Maria Nuova at Florence, without any movement or sign of anything amiss he passed from this life. And I made an anatomy in order to see the cause of so sweet a death which I found to proceed from debility through lack of blood and failure of the artery which feeds the heart and the other lower organs, which I found to be very dried, shrunken and withered. ... The other anatomy was that of a child of 2 years in which I found everything opposite to that of the old man. The old who enjoy good health die through lack of nourishment. This happens because the passage of the mesenteric vessels is continually narrowed by the thickening of the coats of these vessels. And the process continues until it affects the capillary vessels which are the first to close up entirely. As a consequence of this the old dread the cold more than the young, and those that are very old have a skin the colour of wood or dried chestnut because the skin is almost completely deprived of nourishment. The coats of the vessels behave in man as in oranges, in which the peel thickens and the pulp diminishes the older they become. And if you say that it is the thickened blood which ceases to flow through the vessels this is not true, for the blood in the vessels does not thicken because it continually dies and is renewed.

It is to be noted here that Leonardo found no evidence of gross thrombosis in the vessels observed. The sclerosis of the splenic vein described on this page probably reflects the portal hypertension accompanying the hepatic cirrhosis present in this old man. 


\section{News, Notes and Queries}

On Fol. B 11 v. Leonardo is still clarifying the anatomical pattern of the abdominal vessels as shown by his rough diagram in the top left hand corner (see Figure 4). Nevertheless underneath this he writes, 'The vessels are so constricted in the old that the blood loses its movement, decomposes and becomes foul for it can no longer penetrate into the new blood that comes from the gate of the stomach and changes it as it did formerly. Hence the good blood is corrupted on leaving the bowels, and so old people fail without fever when they are of great age.'

On the right hand side of this sketch Leonardo writes, 'One asks why the vessels in the old acquire great length and those which were formerly straight become tortuous and their coat thickens so much as to occlude and prevent the movement of the blood. From this arises the death of the old without disease. I judge that a thing is the more healthy the nearer it is to its nourishment and for this reason these vessels being the sheath of the blood which nourishes the body, are nourished the more in proportion to their nearness to the blood.'

At the foot of the page, near the middle, Leonardo once more sketches tortuous abdominal vessels, commenting below, 'Vessels which by the thickening of their coats in the old restrict the transit of the blood, and from this lack of nourishment the old, little by little with a slow death destroy their life without any fever; and this happens through lack of exercise since the blood is not warmed.'

One further passage about the process of arteriosclerosis is to be found elsewhere in Leonardo's notes on MS. F 1 r., which dates from about 1508. Here he sums up his train of thought as follows-'Death in the old without fever is caused by the coats of the vessels which go from the spleen to the porta hepatis becoming so thick that they are occluded and no longer allow a passage to the blood that feeds them. The continuous passage of blood in these vessels makes them thicken and harden so that in the end they become occluded and prevent the passage of blood. The cavities [lumens] of the vessels of animals with a long course for their nourishing humours become finally contracted and hardened. But the cavities of the vessels of the earth come to be enlarged through the long continuous passage of water.' Here he draws attention to a noteworthy contrast between the formation of caves deep in the body of the earth by water flowing in limestone rocks and the narrowing of the vascular lumens of blood vessels containing the flowing blood in the body of man.

\section{COMMENT}

It is worthy of notice that Leonardo embarked on this dissection of 'the old man' with the announced intention of finding out 'the cause of so sweet a death'. It was therefore primarily a post-mortem in search of pathology. The fact that it eventually constituted an incomparably rich research into normal anatomy was secondary. Moreover, from the pathological point of view, Leonardo considered that his findings satisfactorily answered his question.

Leonardo's view of the essence of corporeal life is reflected in his assertion that 'where there is life there is heat, and where there is vital heat there is movement of the watery humours.' (C.A. 80 r. b). His problem at this autopsy therefore, was to find the cause of that loss of vital heat and movement of the humours coincident with the peaceful death of old age. He found such conditions in the tortuosity and occlusion of 


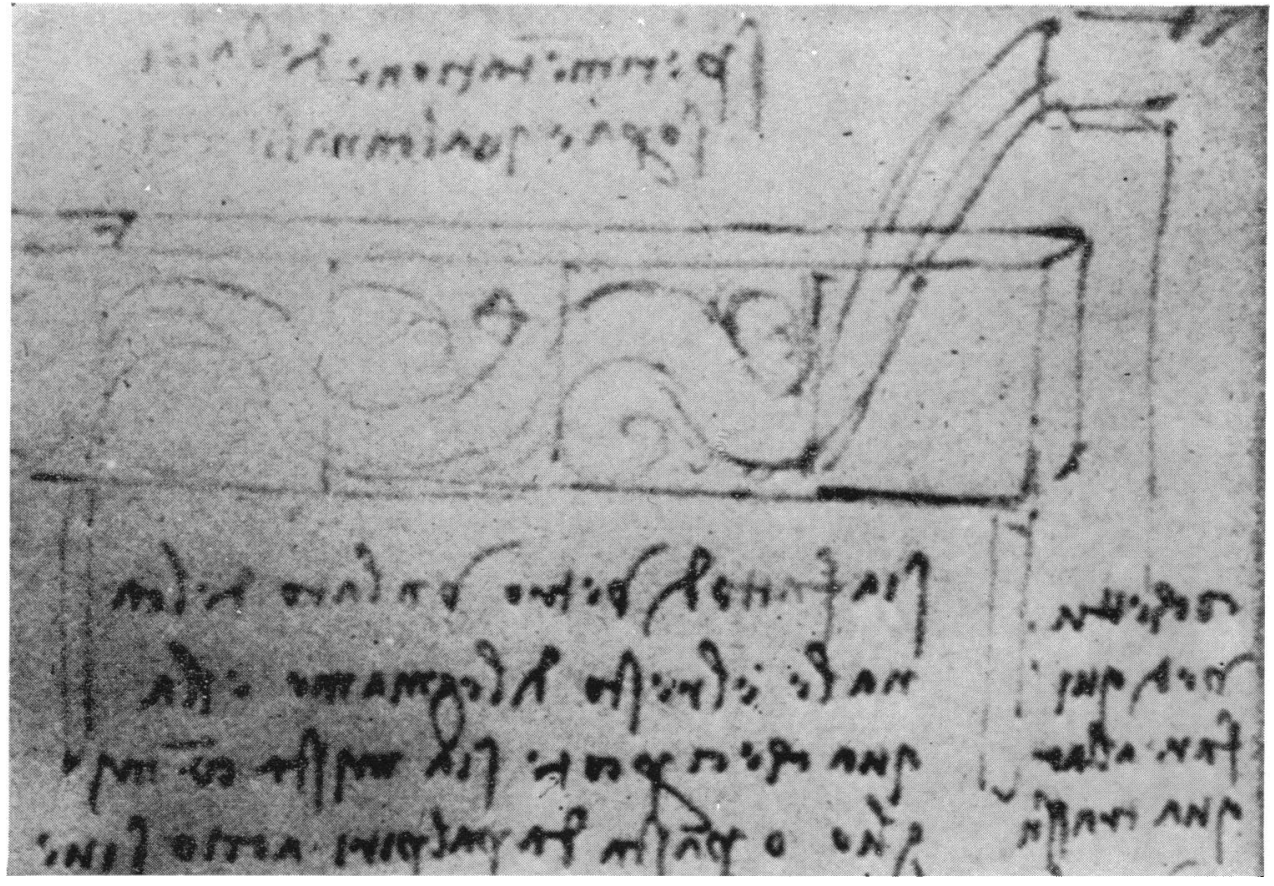

Figure 1

Experiment showing the reflected movement of water from one wall to the other of a glass vessel. Note the eddy formation in the main course of the stream of water. (From MSS. A-M in the Institut de France. Leonardo da Vinci, Les manuscrits publiés en fascimile avec transcriptions literales, traductions etc. par Ravaisson-Mollien, Paris, 1881-1891).

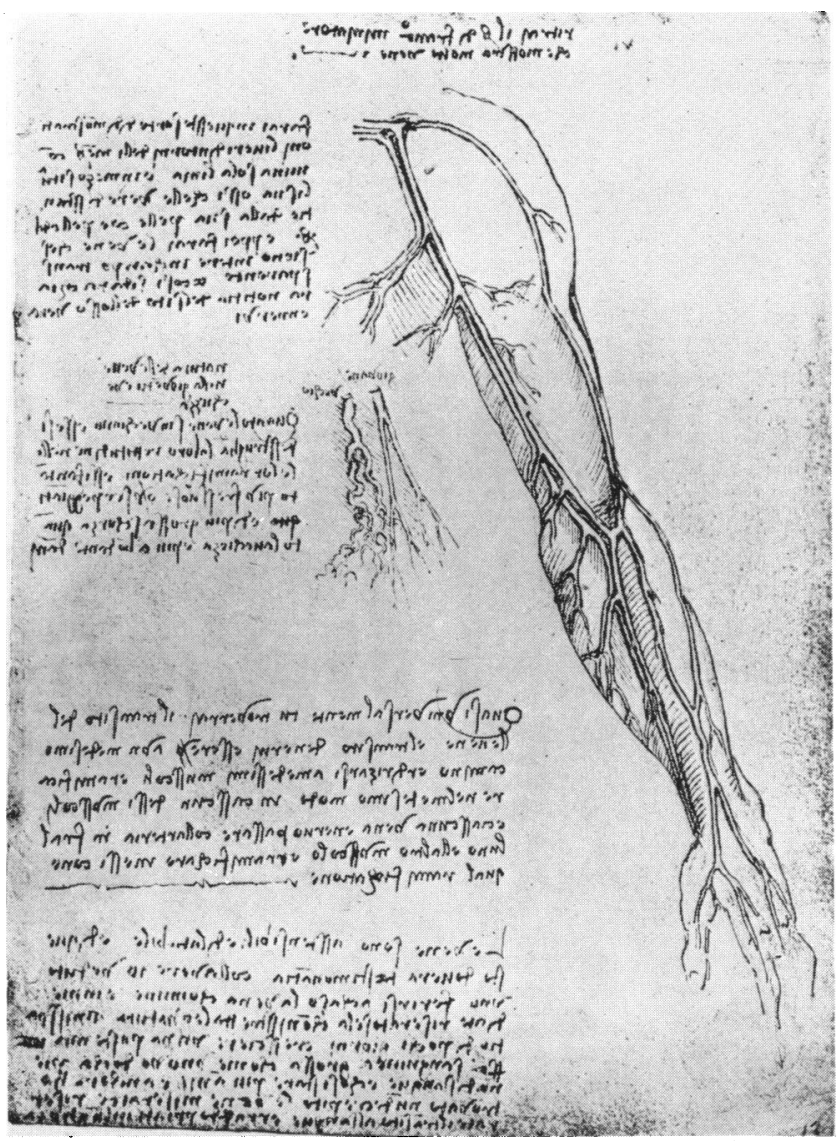

Figure 2

Leonardo depicts the contrast between the straightness of vessels in the young and their tortuosity in the old. The straight vessels in the young man are labelled 'youth', and the tortuous vessels in the old man 'age'. (Fol. B10r). 


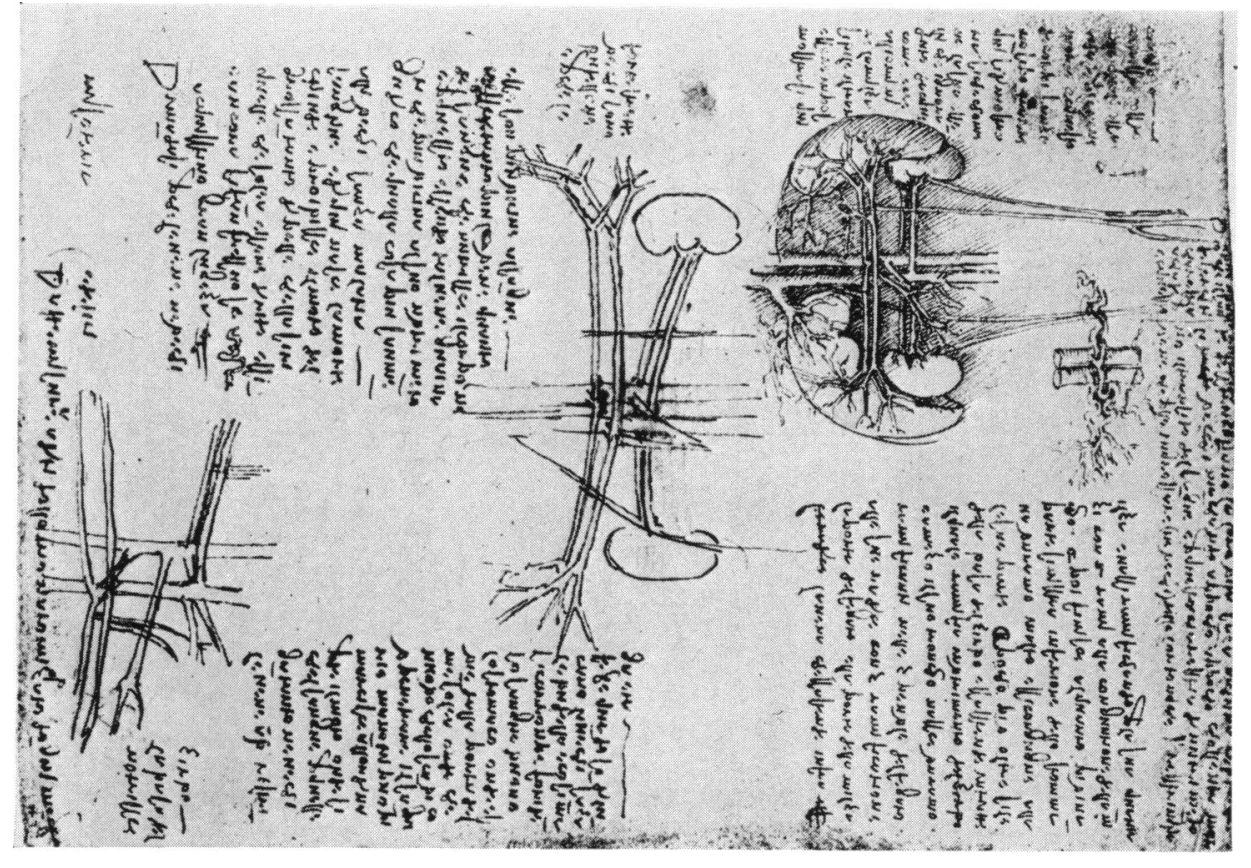

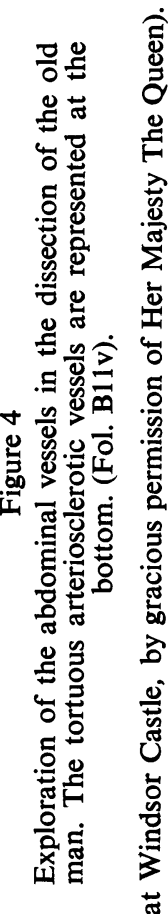

줄

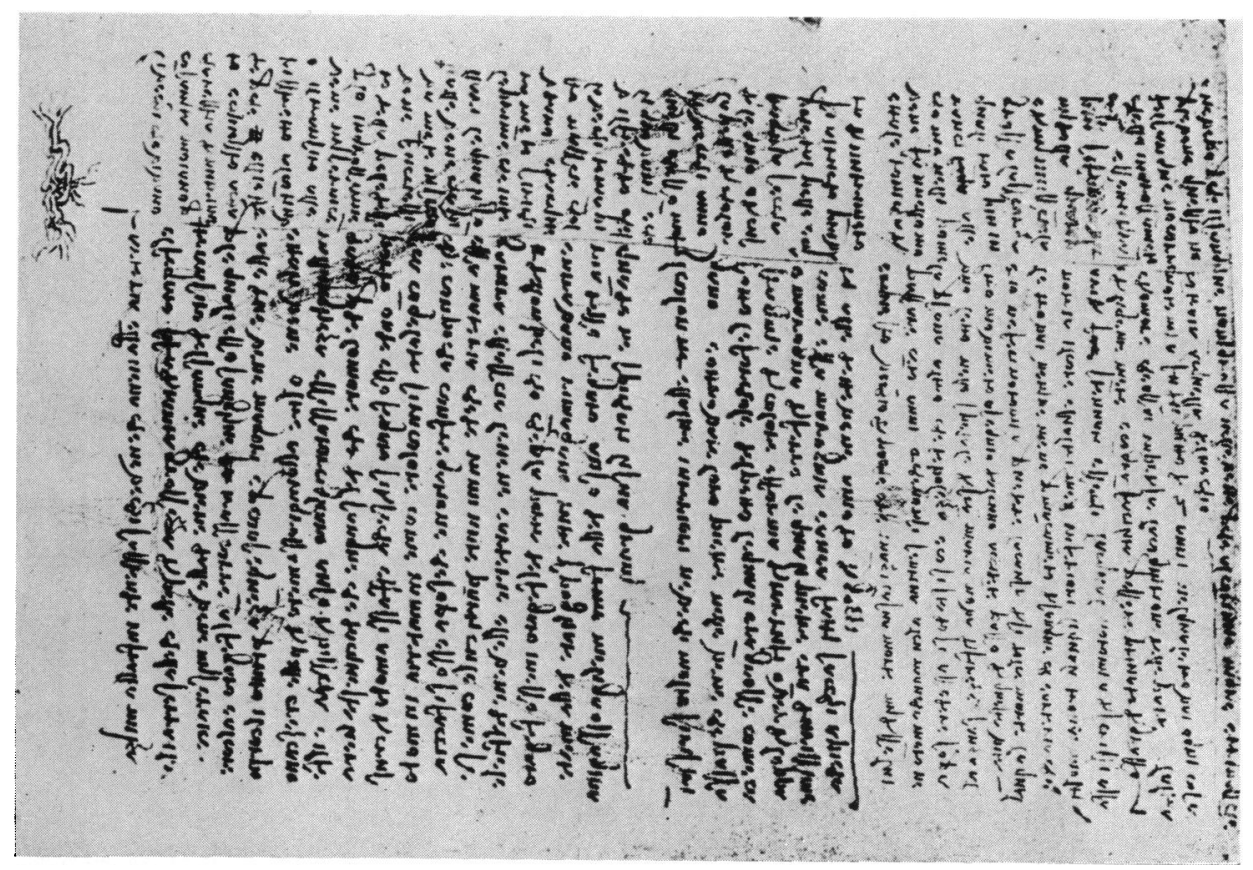

○.

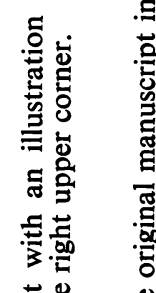

흔훃

$m$ 空嵒

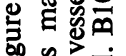

in

훙현

ర్๊ 仓

บั

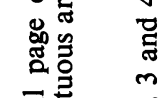

灵吉这 


\section{News, Notes and Queries}

the ramification of the veins and arteries, particularly in the arteries. For like rivers with the passage of time, blood vessels grow in length and become tortuous and for similar hydrodynamic reasons.

The walls of these tortuous blood vessels are nourished by the vital humour, the blood which they contain; forming as it were the sheath of that moving warm blood they obtain an undue proportion of the nutriment contained in the blood. It is this disproportionate nutrition, prolonged over many years, that eventually leads to the undue growth in thickness of the walls. With progressive thickening of the vessel-walls occlusion takes place, particularly at the periphery where they are narrowest. Thus in the old the skin dies 'for lack of sustenance', as do the other organs.

Vascular occlusion moreover, leads to absence of movement, to blood stasis. Lack of movement of blood, as with stagnant water, leads to its putrefaction and its failure to renew itself from food. Physiological heat, in Leonardo's view, was distributed with the blood from the heart through the arterial tree. With vascular narrowing and occlusion, heat distribution to the organs of the body and the skin is diminished, and thus the old feel the cold more keenly than the young, and in this way their organs and tissues eventually die cold, 'without fever'.

All this in Leonardo's view, is the process of natural death from old age as opposed to unnatural death from 'disease'. Natural, normal death he saw as 'sweet'- 'As a well-spent day brings happy sleep, so life well used brings happy death.' (Tr. 27 r.). To Leonardo the physical basis of this 'happy' death consisted of the arteriosclerosis of old age: this aspect of arteriosclerosis has received little attention since.

Leonardo's description of diffuse thickening of the vascular coats in age was bound up with his discovery of their normal anatomy. His reference to the old man's 'death' being due to 'failure of the artery that feeds the heart and lower members' refers to the atheromatous aorta. It has sometimes been forced by the pressure of historians' hindsight into his recognition of coronary occlusion. However, at the time of writing that particular sentence Leonardo had not yet dissected the coronary vessels, a circumstance that renders such an interpretation very improbable.

The term 'arteriosclerosis' for the description of diffuse hardening and thickening of the arteries was not introduced until 1833 by Lobstein. However, many isolated descriptions of atheromatous arterial changes had appeared before then, particularly noteworthy being those of Hunter, Jenner, Parry and Burns in Great Britain at the end of the eighteenth century, and Scarpa's detailed illustrated description of 1804.

Lobstein, like Leonardo, saw the process as due to 'unnatural' nutrition of the arterial wall, and Andral in 1831 confirming that atheromatous changes were commonest in the aorta and splenic artery, attributed them to a derangement of nutrition possibly associated with gout. Thus was 'arteriosclerosis' (later termed 'atherosclerosis' by Marchand in 1904) finally launched on those nutritional and metabolic lines of investigation still being pursued today.

\section{REFERENCES}

'Fol B' refers to I manuscritti di Leonardo da Vinci della Reale Biblioteca di Windsor Dell'Anatomia fogli $B$. pubblicati da Teodoro Sabachnikoff, trascritto ed annotate da Giovanni Piumati, Milan, 1901.

MS. I from MSS. A-M in the Institut de France. Leonardo da Vinci, Les manuscrits publies 


\section{News, Notes and Queries}

en facsimile avec transcriptions literales, traductions etc. par Ravaisson-Mollien, Paris, 1881-1891.

C.A. Il Codice Atlantico nella Biblioteca Ambrosiana di Milano riprodotto e pubblicato dalla Regia Accademia dei Lyncei sotto gli auspici e col sussidio del Governo. Trascrizione di Giovanni Piumati, Rome, 1894-1904.

Tr. Il Codice de Leonardo da Vinci nella biblioteca del Principe Trevulzio in Milano, trascritto ed annatato da Luca Beltrami, Milan, 1891.

ANDral, G., Pathological Anatomy, 1831, 2, 366.

Lobstern, J. F., Traité d'Anatomie Pathologique, 1829-33, 2, 550, quoted from Leibowitz, J. O., The History of Coronary Heart Disease, London, 1970.

LerBowrtz, J. O., The History of Coronary Heart Disease, London, Wellcome Institute of the History of Medicine, 1970, p. 109.

KENNETH D. KEELE

\section{SOME DESCRIPTIONS OF LEPROSY IN THE ANCIENT MEDICAL LITERATURE OF CEYLON*}

\section{INTRODUCTION}

A number of sailing ships under the command of Don Lourenco de Almeida sought sanctuary in a little bay on the west coast of Ceylon on 15 November 1505, having been blown off course while on their way to the Maldive Islands. This little bay was destined to be the modern Colombo harbour, and the chance arrival of the Portuguese in Ceylon in 1505 was to change the course of the island's history as few events have done before, or since.

The population of Ceylon at that time consisted of the Sinhalese, a minority of Tamils who occupied the Jaffna Peninsula in the north, and a largely 'floating' population of Arabs who were there chiefly for purposes of trade. They were not unused to such visitations from foreigners. In fact, the Greeks, Romans, Persians, Chinese and Arabs had all been there at one time or another, and had traded with them or just enjoyed their hospitality. But perhaps unsuspected by the friendly Ceylonese, the Portuguese had quite different ideas. They quickly perceived that the Sinhalese kingdom at Kotte, about six miles away from Colombo, was weak, mainly as a result of dynastic conflicts. By a judicious mixture of cunning and unspeakable acts of terror they took over the control of Colombo, built a fortress there in 1519 and proceeded to extend their area of power over most of the western coastal belt of the island and the Jaffna Peninsula. They also took over,-almost entirely, the island's export trade having persecuted the Arabs who were their principal rivals in this field ruthlessly and systematically.

In 1658, the Dutch overpowered and expelled the Portuguese, and replaced them as controllers of the trade and the rulers of these areas of the island. However, neither the Portuguese nor the Dutch were able to capture the Kandyan kingdom in the central province of Ceylon, in spite of several punitive expeditions to the interior, many of which ended in disastrous massacres of the invading parties.

Meanwhile, the British had been casting side-long glances at Ceylon from their outposts in India for some time, and indeed made some overtures to the King of

*After this article had been accepted for publication, Ceylon became a Republic under the name of Sri Lanka. 